\title{
Molecularly Imprinted Polymer Solid Phase Extraction followed by High-Performance Liquid Chromatography as an Efficient and Sensitive Technique for Determination of Meropenem in Human Plasma and Urine
}

\author{
Hamoon Sami Amlashi $^{(\mathbb{D} \S}$, Ameneh Porgham Daryasari* ${ }^{(\mathbb{D})}$ and Mojtaba Soleimani $^{(\mathbb{D})}$ \\ Department of Chemistry, Lahijan Branch, Islamic Azad University, Lahijan, Iran. \\ Received 10 March 2018, revised 28 December 2018, accepted 20 January 2019.
}

\begin{abstract}
A new and selective sorbent for molecularly imprinted polymer solid-phase extraction (MIP-SPE) was prepared to extract meropenem from plasma and urine samples. The extracted analyte was analyzed by high-performance liquid chromatography (HPLC) coupled with photodiode array detection. Methacrylic acid (MAA) as functional monomer, ethylene glycol dimethacrylate (EGDMA) as cross-linker, azobisisobutyronitrile (AIBN) as an initiator and meropenem as a template molecule were used for the MIP preparation. Imprinted meropenem molecule was removed from the polymeric structure using acetonitrile in water $(1: 9, \mathrm{v} / \mathrm{v})$, as the eluent solvent. Under the optimized conditions, the limit of detection (LOD) and limit of quantification (LOQ) were 35 and $120 \mu \mathrm{g} \mathrm{L}^{-1}$, respectively. The developed MIP-SPE method demonstrates that it could be applied for the determination of meropenem in plasma and urine samples.
\end{abstract}

KEYWORDS

Molecularly imprinted polymer, solid-phase extraction, meropenem, human urine and plasma, high-performance liquid chromatography.

\section{Introduction}

Meropenem is a broad-spectrum carbapenem antibiotic. ${ }^{1}$ It is active against Gram-positive and Gram-negative bacteria. ${ }^{2}$ Meropenem has a known mode of action that penetrates bacterial cells readily and interferes with the synthesis of the vital cell wall components. ${ }^{3}$ Meropenem is an ultra-broad-spectrum injectable antibiotic used to treat a wide variety of infections, including meningitis and pneumonia. ${ }^{4}$ As announced in the scientific notice, ${ }^{5}$ the MIC (minimal inhibition concentration) for the meropenem is very different from one bacteria to another, but very often it is effective in the range $0.5-4 \mu \mathrm{g} \mathrm{mL}^{-1}$ against most sensitive germs.

Unlike imipenem, meropenem is stable against renal dehyropeptidase I(DHP-I ${ }^{6}$ and does not need to be administered with a DHP-I enzyme inhibitor such as cilastatin. ${ }^{7}$ Meropenem therefore has advantages in the intensive care unit (ICU), notably in critically ill patients with renal failure, a population at risk for accumulating co-administered drugs or metabolites. ${ }^{8}$

It is very important that an adequate and safe level of the drug is achieved in plasma and in cerebrospinal fluid (CSF) for treatment of several bacterial infections with meningitis. Meropenem displays a time-dependency whereby bactericidal activity correlates with the duration that serum drug concentration remains above $\mathrm{MIC}_{90}$ (minimum inhibitory concentration required to inhibit the growth of $90 \%$ of organisms) for the organism. The $\mathrm{MIC}_{90}$ value of meropenem concentration for Pseudomonas aeruginosa and penicillin and cephalosporinresistant Streptococcus pneumoniae are less than $0.5 \mu \mathrm{g} \mathrm{mL}^{-1}$ and $1.0 \mu \mathrm{g} \mathrm{mL}^{-1}$, respectively. Therefore, the meropenem concentration in CSF would be above the MIC.

High-performance liquid chromatographic (HPLC) tech- niques are most commonly employed clinically for analyzing meropenem. Microbiological assays ${ }^{10,11}$ have been reported for meropenem, but these procedures suffer from a lack of selectivity and are time-consuming. The MBA was performed by using Escherichia coli NIHJ as the test strain. The medium used was nutrient agar (Difco Laboratories; $\mathrm{pH}$ 6.6). The plates were incubated overnight at $37^{\circ} \mathrm{C}$. Linear regression analysis of the standard calibration lines obtained by plotting log antibiotic concentrations versus zone diameters of inhibition indicated excellent linearity of the assay between 0.08 and $5.00 \mu \mathrm{g} \mathrm{mL}^{-1}$. The sensitivity limit of the assay was $0.08 \mu \mathrm{g} \mathrm{mL}^{-1}$. The coefficients of variation of the assay were $5 \%$ at $5 \mu \mathrm{g} \mathrm{mL}^{-1}$ and $9 \%$ at $0.08 \mu \mathrm{g} \mathrm{mL}^{-1}$. The recovery of meropenem in urine at $24 \mathrm{~h}$ was $65.4 \%$ by microbiological assay.

Solvent extraction, ${ }^{12}$ solid phase extraction ${ }^{13}$ and column switching method ${ }^{14,15}$ have been used as sample pretreatment for determination of meropenem. High-performance liquid chromatography-mass spectrometry (LC-MS) assays have been developed to analyze meropenem. ${ }^{16,17}$ However, they are expensive and not generally available.

Molecularly imprinted polymers (MIPs) are highly stable polymers that possess recognition sites within the polymer matrix. These molecularly imprinted polymers can be produced in a covalent or a non-covalent manner. ${ }^{18}$ The interactions between the template and the monomers are based on hydrogen bonds and ionic and hydrophobic interactions. ${ }^{19} \mathrm{MIP}$ can be packed in disposable cartridges for off-line SPE or in columns for on-line SPE. The classical SPE sorbents such as C18, ion-exchange and size-exclusion phases are lacking in selectivity towards target analytes. In order to overcome this drawback, the use of MIP in SPE (MIP-SPE) has been developed. ${ }^{20,21}$

MIP-SPE allows not only the analyte to be pre-concentrated 
but also the other compounds present in the sample matrix to be removed. The aim of this study was to develop a simple, sensitive and low-cost method based on MIP as selective SPE sorbents for the determination of meropenem in plasma and urine samples. To the best of our knowledge, no report has been published on MIP-SPE of meropenem.

\section{Experimental}

\subsection{Reagents and Chemicals}

Ceftazidime, meropenem and cefixime were obtained from JaberEbneHayyan Pharmaceutical Company (Tehran, Iran). Isoniazid was obtained from Daroupakhsh Distribution Company (Tehran, Iran). Methacrylic acid (MAA), ethylene glycol dimethacrylate (EGDMA), 2, 2-azobis isobutyronitrile (AIBN), methanol and chloroform were obtained from Merck (Darmstadt, Germany). Acetonitrile HPLC grade was obtained from DAEJUNG (Korea). The water used was purified on a Youngling ultrapure water purification system (AquaMAXTM, Ultra 370 Series, Korea). Deionized water was used in all experiments. The stock solution (1000 $\left.\mathrm{mg} \mathrm{L}^{-1}\right)$ of meropenem was prepared in HPLC-grade water (DAEJUNG , Korea) and stored at $-4{ }^{\circ} \mathrm{C}$. Working solutions with different concentrations were prepared daily.

\subsection{Apparatus}

HPLC analysis was performed using a Shimadzu (LC-20AD Prominence, Japan) with a diode array detector (SPD-M20A). Separations were carried out on a $\mu$ Boundapak C18 column of $3.9 \mathrm{~mm} \times 150 \mathrm{~mm}$ with $10 \mu \mathrm{m}$ film thickness HPLC column. HPLC data were acquired and processed using a Lab solution software (LC solution version 1.25 SP5). A mixture of acetonitrile/acetate buffer $(\mathrm{pH} 7.0)(40: 60, \mathrm{v} / \mathrm{v})$ at the flow rate of 1.0 $\mathrm{mL} \mathrm{min}^{-1}$ was used as a mobile phase in the isocratic mode. The injection volume for all of the sample was $25 \mu \mathrm{L}$ and detection wavelength was set at $299 \mathrm{~nm}$. pH of solutions was adjusted using a Metrohm $\mathrm{pH}$ meter equipped with a combined glasscalomel electrode (model 827 digital, Swiss). FT-IR spectra $\left(400-4000 \mathrm{~cm}^{-1}\right)$ in $\mathrm{KBr}$ was recorded on a Bruker spectrometer (Alpha, USA).

TG/DTG analyses were performed using a LINSEIS Model STA PT-1600 (Germany) instrument, under nitrogen, up to $600{ }^{\circ} \mathrm{C}$, with a linear heating rate of $10{ }^{\circ} \mathrm{C} \mathrm{min}^{-1}$.

\subsection{Synthesis of Molecularly Imprinted Polymer}

For the preparation of the MIP, meropenem $(0.5 \mathrm{mmoL})$ was dissolved in chloroform and then MAA (2 mmoL), EGDMA (10 mmoL) and AIBN (0.272 mmoL) were added to the solution. The mixture was shaken and degassed with a stream of $\mathrm{N}_{2}$ for $10 \mathrm{~min}$ and the glass tube was sealed and heated at $60^{\circ} \mathrm{C}$ for $24 \mathrm{~h}$. After polymerization process, the resulting polymer was crushed and dried. Afterward template molecule (meropenem) in the MIP removed by soxhlet extraction with the mixture of methanol and glacial acetic acid $(8: 2, \mathrm{v} / \mathrm{v})$. For comparison, NIP (polymer without meropenem) was prepared as a blank in the same procedure but without the addition of meropenem (as a template molecule). The MIP sorbent's lifetime was investigated by monitoring the change of extraction efficiencies obtained by performing repeated extractions under optimized experimental conditions with a definite amount of sorbent. The sorbent regeneration was carried out using methanol after each extraction step. It was established that sorbent could be used with no obvious decline in performance for about six extraction/desorption cycles.

\subsection{MIP-SPE Procedure}

SPE column was prepared by packing $100 \mathrm{mg}$ of the polymer into a $5 \mathrm{~mL}$ empty cartridge. The cartridge was conditioned sequentially with $5 \mathrm{~mL}$ of methanol and $20 \mathrm{~mL}$ of distilled water. Extraction experiments involved loading the column with $100 \mathrm{~mL}$ of sample solution (urine and plasma) meropenem $(\mathrm{pH}$ 7.0) at a flow rate of $2 \mathrm{~mL} \mathrm{~min}^{-1}$. After loading, a column was washed with $5 \mathrm{~mL}$ of acetone, and a full vacuum (Full Vacuum, generally taken as 1 atmosphere pressure external to the vessel, with zero absolute pressure inside, equivalent to 15 PSIG external pressure) was applied to the cartridge for $1 \mathrm{~min}$ to remove residual solvent. Finally, the elution was performed by passing $5 \mathrm{~mL}$ of acetonitrile/water $(1: 9, \mathrm{v} / \mathrm{v})$. Then, $25 \mu \mathrm{L}$ of each sample was injected into the HPLC system for analysis.

\subsection{Template Removing}

After the preliminary polymer preparation mentioned earlier, in order to the template removal, the template was removed by soxhlet extraction. ${ }^{24}$ The template was washed with $300 \mathrm{~mL}$ methanol:acetic acid $(8: 2,(\mathrm{v} / \mathrm{v}))$ for $18 \mathrm{~h}$ at $80^{\circ} \mathrm{C}$. To ensure full removal of template molecule, MIP were washed with methanol:acetic acid $(8: 2(\mathrm{v} / \mathrm{v}))$ for $30 \mathrm{~min}$ several times. Then, it was washed with distilled water several times to remove acetic acid. Finally, the polymer was dried and crushed.

\subsection{FT-IR Analysis}

Fourier-transform infrared spectroscopy (FTIR) characterization was performed to determine the functional groups in MIP before (first MIP) and after (final MIP) the soxhlet stage and also in NIP (polymer without meropenem (Fig. 1). All spectra obtained from polymers exhibit similar peaks, indicating a common polymer structure in all of them. The absence absorption bands in the region $1638-1648 \mathrm{~cm}^{-1}$ due to the absence of free vinyl groups in polymer particles. Therefore, it can be concluded that all vinyl groups of MAA and EGDMA are involved in polymerization. The absorption band of the carbonyl group appears in $1720 \mathrm{~cm}^{-1}$, but after the polymerization reaction with a cross-linking and a reduction of conjugation, this absorption band is shifted to $1726 \mathrm{~cm}^{-1}$. As a result, a strong peak appeared in the range of $1720-1725 \mathrm{~cm}^{-1}$. Absorbance at $3444-3452 \mathrm{~cm}^{-1}$ indicates $\mathrm{O}-\mathrm{H}$ band, where the intensity for MIP before soxhlet is lower than that for MIP after soxhlet. A plausible reason for this phenomenon is that the template molecule (meropenem) is assembled with monomer (MAA) via hydrogen bonding with $\mathrm{O}-\mathrm{H}$ during the preparation of MIP prior to washing. However, after the template removal, a strong and broad stretching vibration absorbance peak of $\mathrm{O}-\mathrm{H}$ from monomer is clearly observed due to the absence of any hydrogen bond disruption. ${ }^{22,23}$

\subsection{Thermogravimetric Analysis}

Thermal stability of the synthesized molecularly imprinted polymer was evaluated by thermogravimetric analyzer. Figure 2 shows TG/DTGA plots for the molecularly imprinted polymer. The little weight loss in earlier temperature is due to physically combined water. The second stage of weight loss is related to exclusion of remaining organic solvents and combustion of organic part. GA plot for MIP can prove the thermal stability of the synthesized polymer. The percentage of mass loss for MIP was studied up to $600{ }^{\circ} \mathrm{C}$. The polymer has not completely decomposed at this temperature, although, the total mass loss of MIP was about $56.19(\mathrm{~m} / \mathrm{m} \%)$.

\subsection{Effect of $\mathrm{pH}$}

To evaluate the effect of $\mathrm{pH}$, a working solution with different 


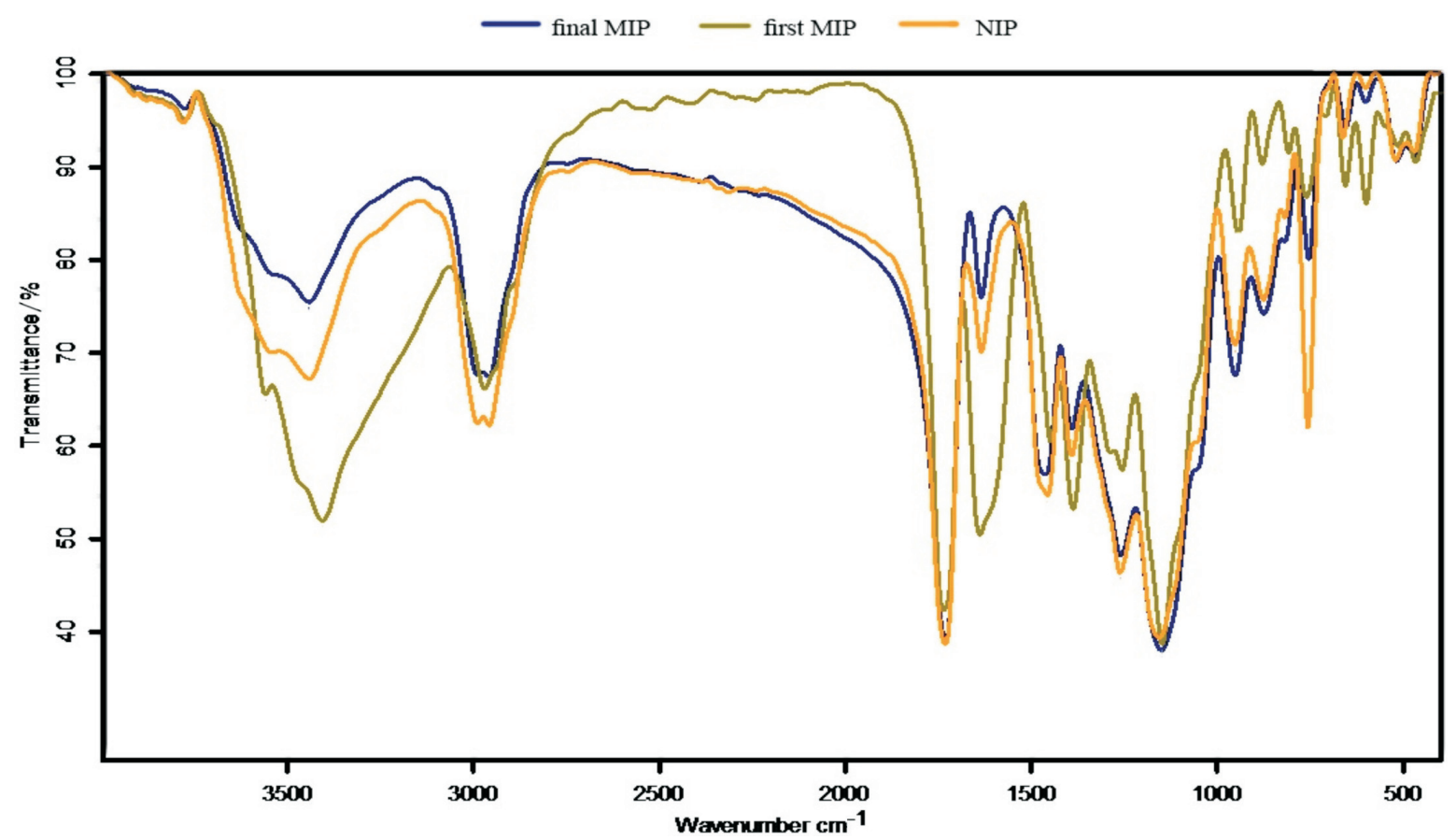

Figure 1 FT-IR spectra of MIP before (first MIP) and after (final MIP) the soxhlet stage and NIP (polymer without meropenem).

$\mathrm{pH}$ in the range of 3-9 was studied. The $\mathrm{pH}$ of samples was adjusted with $1 \mathrm{~mol} \mathrm{~L}^{-1}$ of $\mathrm{NaOH}$ and $\mathrm{HCl}$. As shown in Fig. 3, the highest adsorption of meropenem was obtained at $\mathrm{pH}$ 7. In $\mathrm{pH}<7$, because of high concentration of proton ion and protonation of the carboxylic groups in MIP and in $\mathrm{pH}>7$, because of deprotonation of meropenem, interaction between MIP and meropenem does not happen, hence, extraction efficiency decreases. Thus, the $\mathrm{pH} 7$ was selected as optimized $\mathrm{pH}$ according to the findings from the present results.

It is mentioned that the extraction recovery was obtained with the following equation:

$$
\operatorname{ER}(\%)=\frac{\mathrm{C}_{0}}{\mathrm{C}_{\mathrm{a}} \times \mathrm{D}} \times \frac{\mathrm{V}_{0}}{\mathrm{~V}_{\mathrm{a}}} \times 100
$$

where $\left(\mathrm{C}_{\mathrm{a}}, \mathrm{V}_{\mathrm{a}}\right),\left(\mathrm{C}_{0}, \mathrm{~V}_{0}\right)$ and $\mathrm{D}$ are the concentrations and volumes of meropenem before and after extraction in the solution and dilution factor, respectively.

\subsection{Type of Elution Solution}

The eluting step was optimized to damage the special interaction taking place between meropenem and MIP. ${ }^{25,26}$ Methanol, methanol-hydrochloric acid $(0.01 \mathrm{M})$, methanol-acetic acid $(0.1$ $\mathrm{M})$, acetonitrile-water $(2: 8, \mathrm{v} / \mathrm{v})$, acetonitrile-water $(3: 7, \mathrm{v} / \mathrm{v})$, acetonitrile-water $(9: 1, \mathrm{v} / \mathrm{v})$ and acetonitrile-water $(1: 9, \mathrm{v} / \mathrm{v})$ were investigated as elution solution. The results (Fig. 4) show that acetonitrile-water $(1: 9, \mathrm{v} / \mathrm{v})$ as elution solution provided the best recovery for meropenem. It is probable that this solvent more

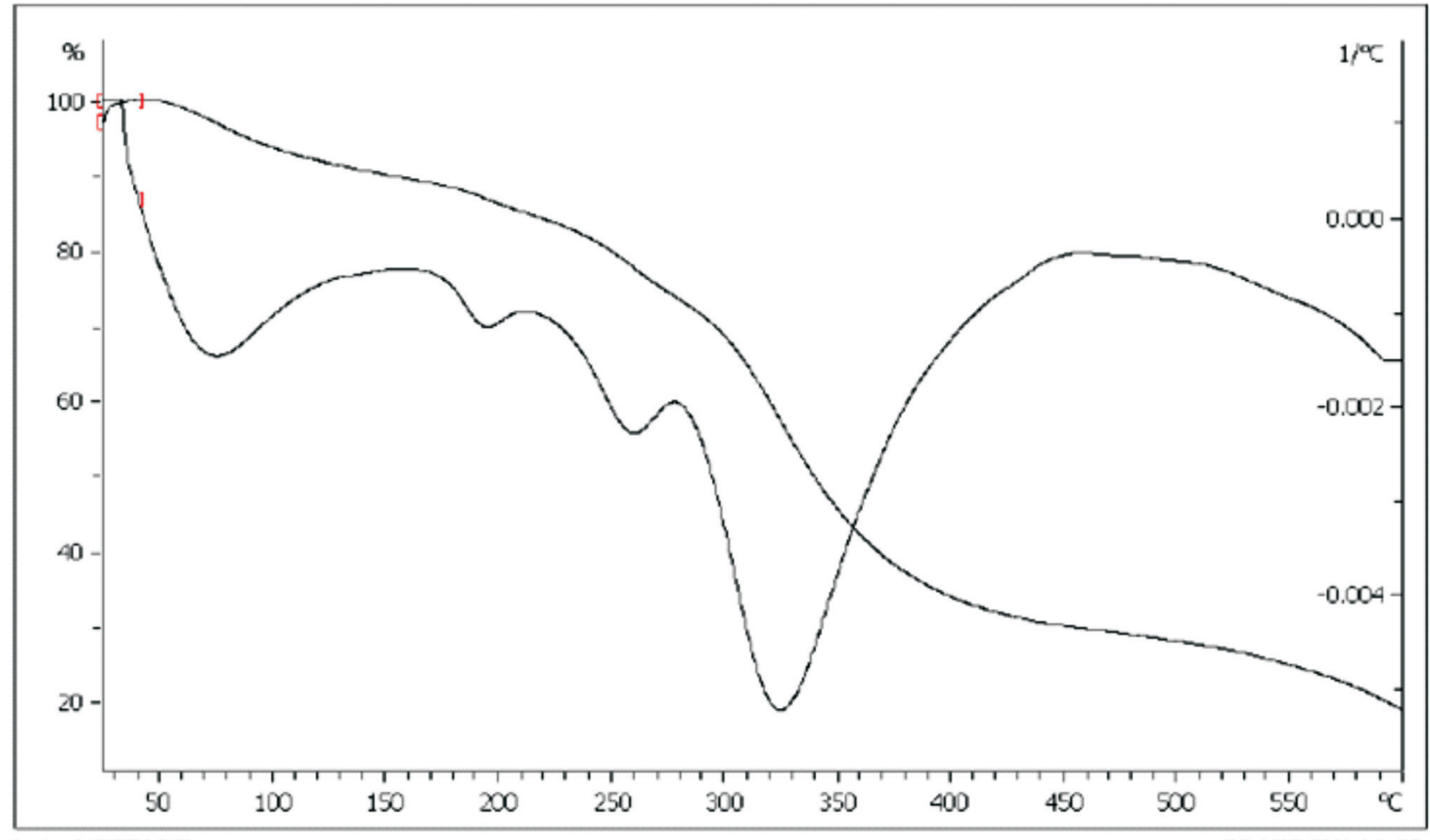

Lab: MEITLER

Figure 2 TG/DTG analyses plot for the molecularly imprinted polymer. 


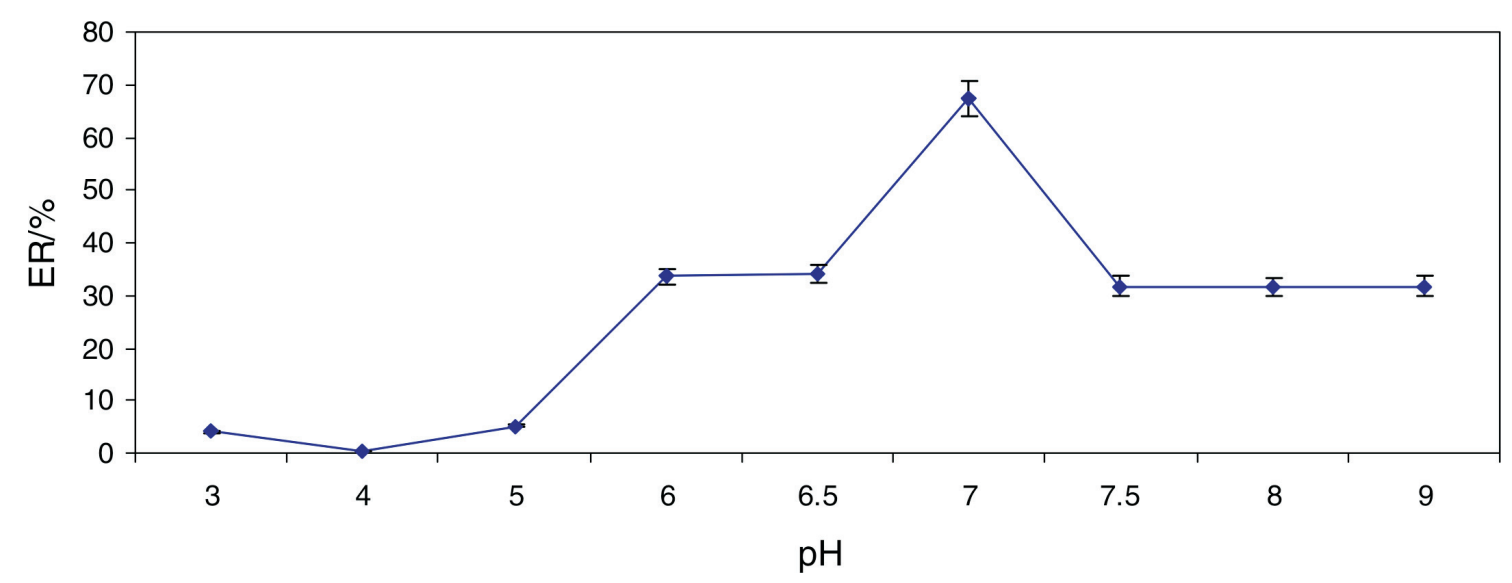

Figure 3 Effect of $\mathrm{pH}$ on the extraction efficiency of MIP-SPE of meropenem $(\mathrm{n}=3)$.

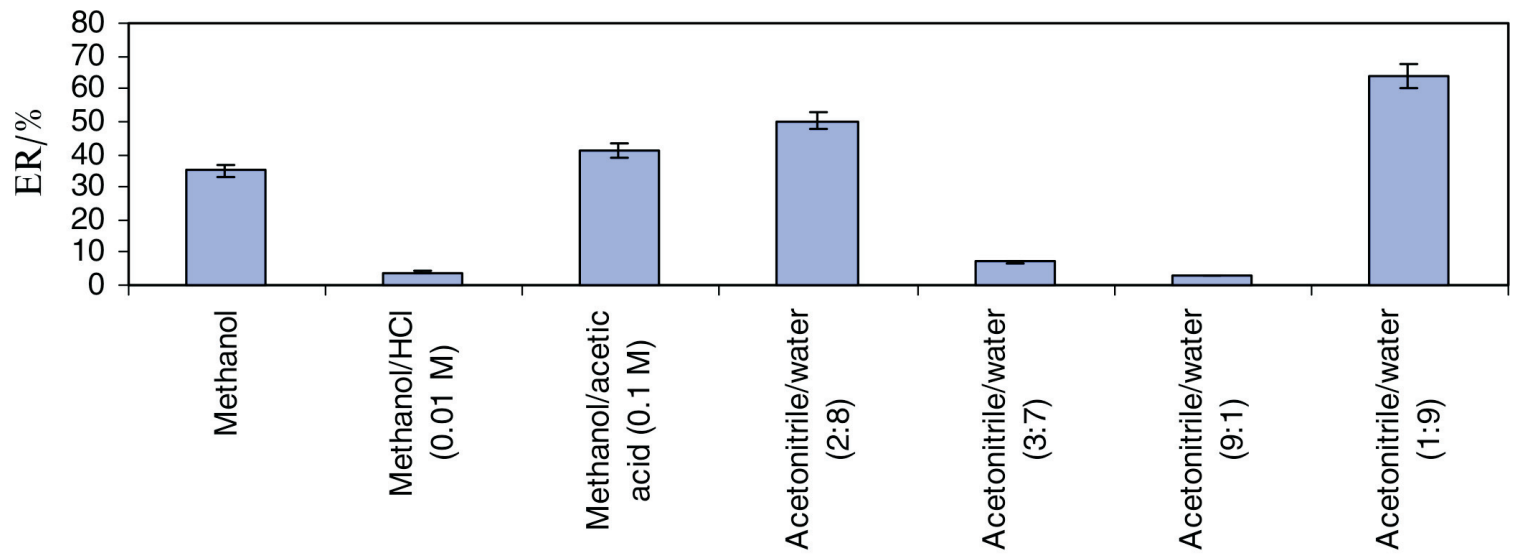

Type of elution solvent

Figure 4. Effect of type of elution solvent on the extraction efficiency of MIP-SPE of meropenem $(n=3)$.

successfully damages hydrogen bonding between meropenem and methacrylic acid.

\subsection{Effect of the Flow Rate of the Sample Solution}

The effect of flow rate on the recoveries of the analyte was investigated in the range of $1.5-6 \mathrm{~mL} \mathrm{~min}^{-1}$. It was found that at $2 \mathrm{~mL} \mathrm{~min}^{-1}$, the best recovery was obtained (Fig. 5). It seems that at the lower flow rate of the sample solution there is enough time to retain meropenem in the sorbent.

\subsection{Effect of the Flow Rate of the Elution Solvent}

The effect of the flow rate of the elution solvent was studied in the range of $0.5-1.5 \mathrm{~mL} \mathrm{~min}^{-1}$. At the flow rate of $0.5 \mathrm{~mL} \mathrm{~min}^{-1}$, the maximum extraction efficiency was observed. It is probably that at the lower flow rate, the elution solvent has enough time for the desorption of meropenem.

\subsection{Effect of the Sample Volume}

In order to determine the optimum loading volume, experiments were carried out on using various sample volumes ranging from $20 \mathrm{~mL}$ to $125 \mathrm{~mL}$ and the extraction efficiency was investigated. It was found that the highest recovery was attained when the sample volume was at $100 \mathrm{~mL}$. Hence, $100 \mathrm{~mL}$ was selected as the optimal sample volume.

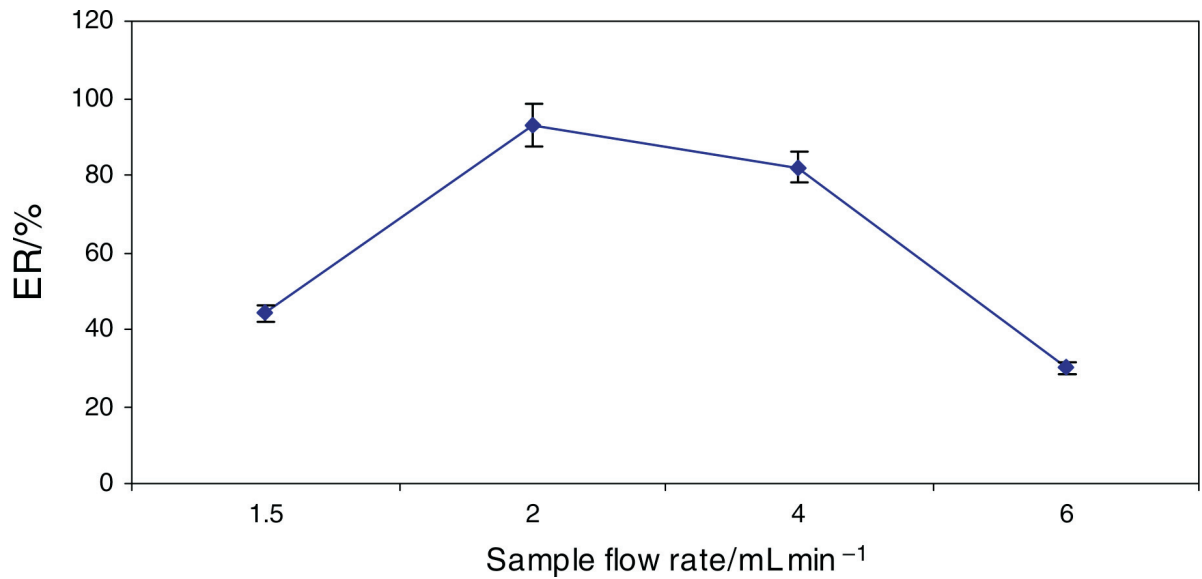

Figure 5 Effect of flow rate of the sample solution on the extraction efficiency of MIP-SPE of meropenem $(n=3)$. 


\subsection{Effect of the Sorbent Amount}

The effect of sorbent amount was investigated in the range of $0.1-0.5 \mathrm{~g}$. In the range of 0.1 to $0.5 \mathrm{~g}$, sorption levelled off and remained unchanged (Fig. 6). Therefore, it was decided to use $0.1 \mathrm{~g}$ sorbent in the remaining experiments.

\section{Results and Discussion}

\subsection{Selectivity Test}

Ceftazidime, cefixime and isoniazid were selected as competitive compounds to estimate the selectivity of MIPs for mero- penem. The structures of these drugs are shown in Fig. 7. The results are shown in Fig. 8. The results indicate that the extraction recovery of cefixime is high, which resulted from its structural similarity to meropenem. Although ceftazidime had similar structure to meropenem, but MIPs had low affinity for ceftazidime, because the obtained optimum extraction conditions for meropenem are not suitable for ceftazidime. Also, MIPs had low affinity for isoniazid, because of different structure with meropenem. Non-imprinted polymer (NIP) had low extraction recovery for the drugs, because of absence binding sites in NIP and low absorption performance (Fig. 8).

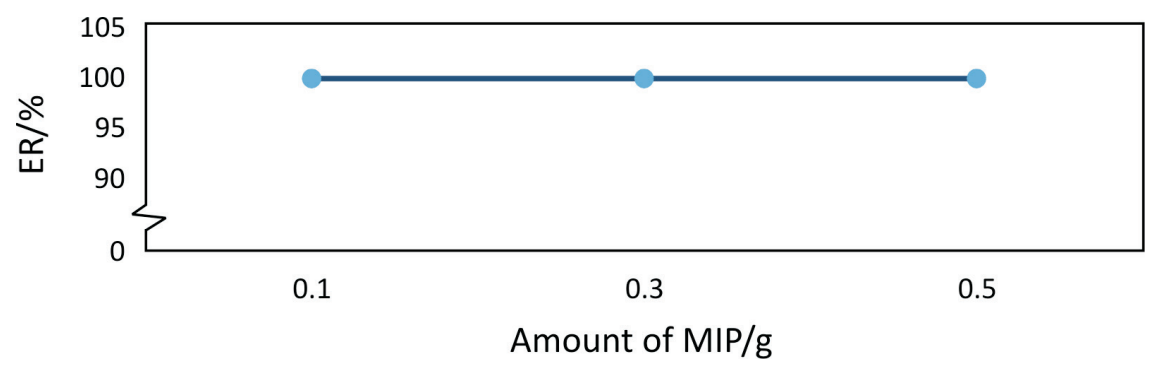

Figure 6 Effect of sorbent amount on the extraction efficiency of MIP-SPE of meropenem.<smiles></smiles>

Ceftazidime<smiles>COC(=O)C1=C(S[C@@H]2CN[C@H](C(=O)N(C)C)C2)C(C)[C@@H]2N1C(=O)[C@]2(O)C(C)O</smiles><smiles>C=CC1=C(C(=O)O)N2C(=O)[C@H](NC(=O)/C(=N/OCC(=O)O)c3csc(N)n3)[C@H]2SC1</smiles>

Cefixime<smiles>NNC(=O)c1ccncc1</smiles>

Isoniazid

Figure 7 Schematic structures of ceftazidime, cefixime, meropenem and isoniazid.

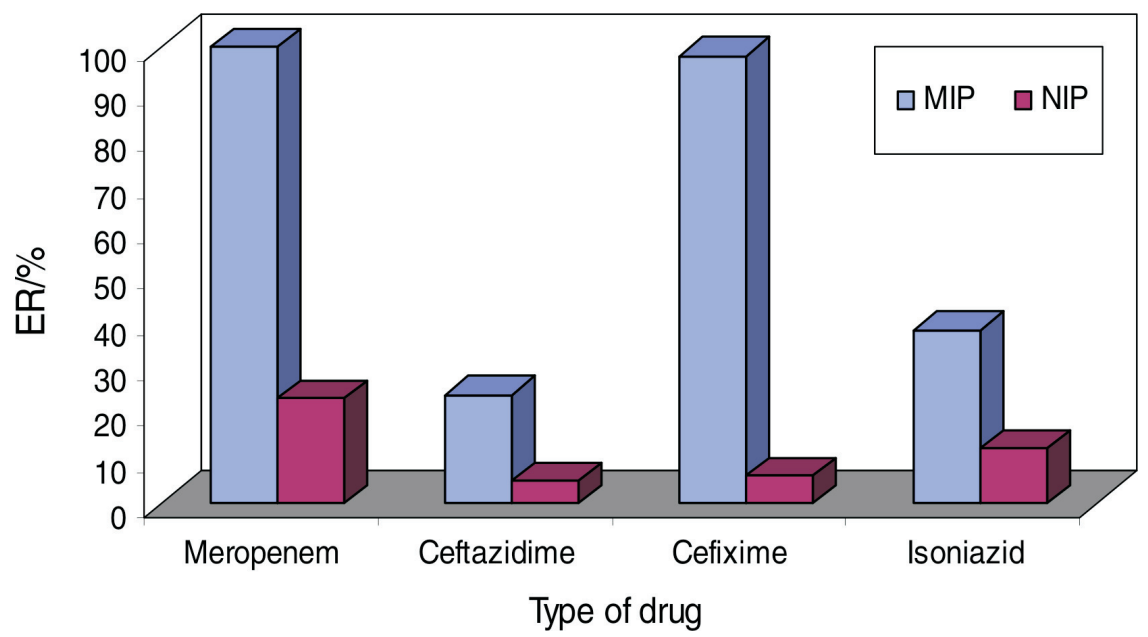

Figure 8 Selectivity of MIP and NIP for ceftazidime, cefixime, meropenem and isoniazid. 


\subsection{Adsorption Capacity}

The capacity of the sorbent is an important factor that defines how much sorbent is required to remove a specific amount of drug from the solution quantitatively. To measure the adsorption capacity, $100 \mathrm{mg}$ of MIP or NIP was mixed with $100 \mathrm{~mL}$ meropenem solutions at concentrations of $5.0-50 \mathrm{mg} \mathrm{L}^{-1}$. The suspensions were shaken for $2 \mathrm{~h}$ at room temperature and then centrifuged. The remained meropenem in the supernatant was measured by HPLC. According to these results (Fig. 9), the $\backslash$ maximum amount of meropenem that can be adsorbed by MIP was found to be $219.6 \mathrm{mg} \mathrm{g}^{-1}$. The maximum amount of meropenem that can be adsorbed by NIP was found to be $23 \mathrm{mg} \mathrm{g}^{-1}$.

\subsection{Quantitative Aspects}

Calibration curve was obtained under optimized conditions. Linearities were was observed over the range $120-800 \mu \mathrm{g} \mathrm{L}^{-1}$ for the analyte in the urine and plasma samples. The coefficient of determination $\left(\mathrm{r}^{2}\right)$ of calibration graphs were 0.9997 and 0.9989 in the urine and plasma samples, respectively. The relative standard deviation (RSD, $\mathrm{n}=5$ ) at three different concentration levels of meropenem in urine and plasma are shown in Table 1.
The LOD (limit of detection) and LOQ (limit of quantitation) are often defined as the concentrations which yield a measure peak with $\mathrm{S} / \mathrm{N}$ of 3 and 10 , respectively. In the urine sample, the LOD and LOQ were 35 and $120 \mu \mathrm{g} \mathrm{L}^{-1}$, respectively. In the urine and plasma sample, the LOD and LOQ were 35 and $120 \mu \mathrm{g} \mathrm{L}^{-1}$, respectively.

Table 2 compares the proposed method with other extraction methods for determination of meropenem. Quantitative results of the proposed method are better than of the other methods $\mathrm{s}^{20-22}$ for the determination of meropenem. The prepared MIP have very good performance for selective extraction of meropenem. Other advantages of the suggested method are: lack of matrix effect, low consumption of organic solvent.

\subsection{Extraction of the Meropenem from Human Urine and \\ Plasma}

Due to the importance of analysis of meropenem in human urine and plasma, the proposed method was applied to determine the concentration of the analyte in the urine and plasma samples, and the obtained results are summarized in Table 3. The urine from a healthy person was collected in disposable polyethylene containers and kept at $4{ }^{\circ} \mathrm{C}$ before analysis. A

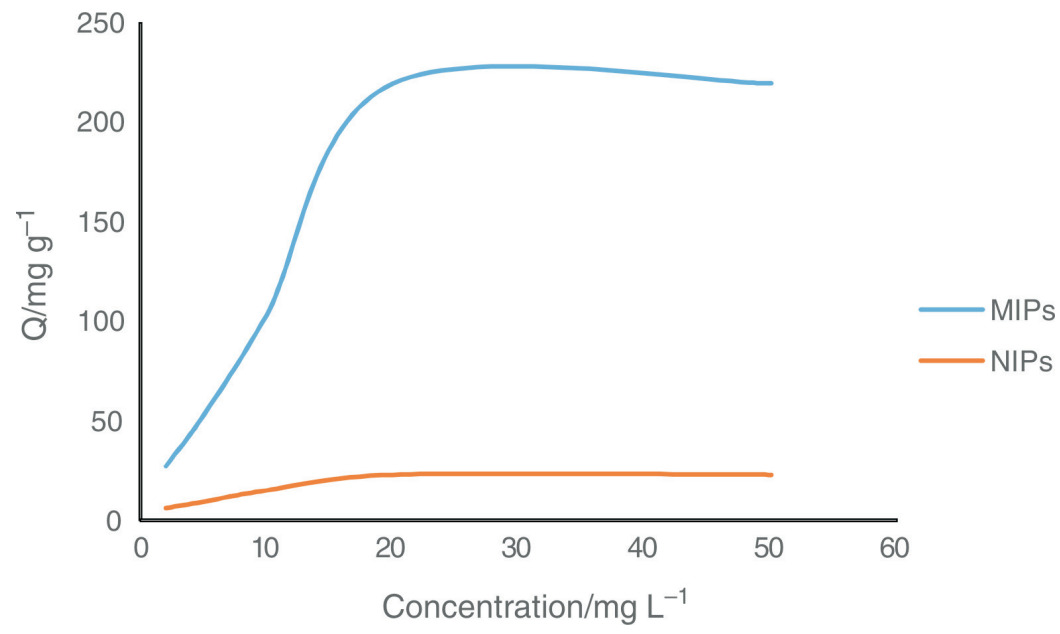

Figure 9 Adsorption capacity of MIP and NIP for meropenem.

Table 1 Relative standard deviation $(\mathrm{RSD} / \%)(\mathrm{n}=5)$ at three concentration levels of meropenem.

\begin{tabular}{ccc}
\hline \multirow{2}{*}{$\begin{array}{c}\text { Concentration of meropenem } \\
/ \mu \mathrm{g} \mathrm{L}^{-1}\end{array}$} & \multicolumn{2}{c}{$\mathrm{RSD} / \%$} \\
\cline { 2 - 3 } & Urine & Plasma \\
\hline \multirow{2}{*}{120} & 6.0 & 7.3 \\
250 & 4.4 & 6.5 \\
500 & 3.1 & 5.0 \\
\hline
\end{tabular}

Table 3 Determination of meropenem in human plasma and urine by MIP-SPE-HPLC-DAD.

\begin{tabular}{lcc}
\hline Sample & $\begin{array}{c}\text { Spiked concentration } \\
\left(\mu \mathrm{g} \mathrm{L}^{-1}\right)\end{array}$ & $\begin{array}{c}\text { Relative recovery } \% \pm \mathrm{RSD} \\
(\mathrm{n}=3)^{\mathrm{a}}\end{array}$ \\
\hline Human urine & 400 & $93.0 \pm 3.6$ \\
& 600 & $90.0 \pm 2.8$ \\
Human plasma & 400 & $95.0 \pm 5.6$ \\
& 600 & $88.3 \pm 4.7$ \\
\hline
\end{tabular}

a Relative standard deviation.

Table 2 Comparison of the proposed method with other extraction methods for determination of the meropenem.

\begin{tabular}{|c|c|c|c|c|}
\hline Method & \%R.S.D. & Dynamic linear range $/ \mu \mathrm{g} \mathrm{L}^{-1}$ & Limit of detection $/ \mu \mathrm{g} \mathrm{L}^{-1}$ & Ref. \\
\hline $\begin{array}{l}\text { Solid-phase extraction-micellar electrokinetic } \\
\text { capillary chromatography }\end{array}$ & 3.1 & $500-50000$ & 200 & [27] \\
\hline Solid-phase extraction-HPLC-UV & 2.0 & $2500-60000$ & $\begin{array}{c}500 \\
\text { (limit of quantification) }\end{array}$ & [28] \\
\hline Solid-phase extraction-HPLC-UV & 6 & 125-2000 & $\begin{array}{c}125 \\
\text { (limit of quantification) }\end{array}$ & [29] \\
\hline MIP-SPE-HPLC-DAD & $2.8-5.6$ & $120-800$ & 35 & This work \\
\hline
\end{tabular}




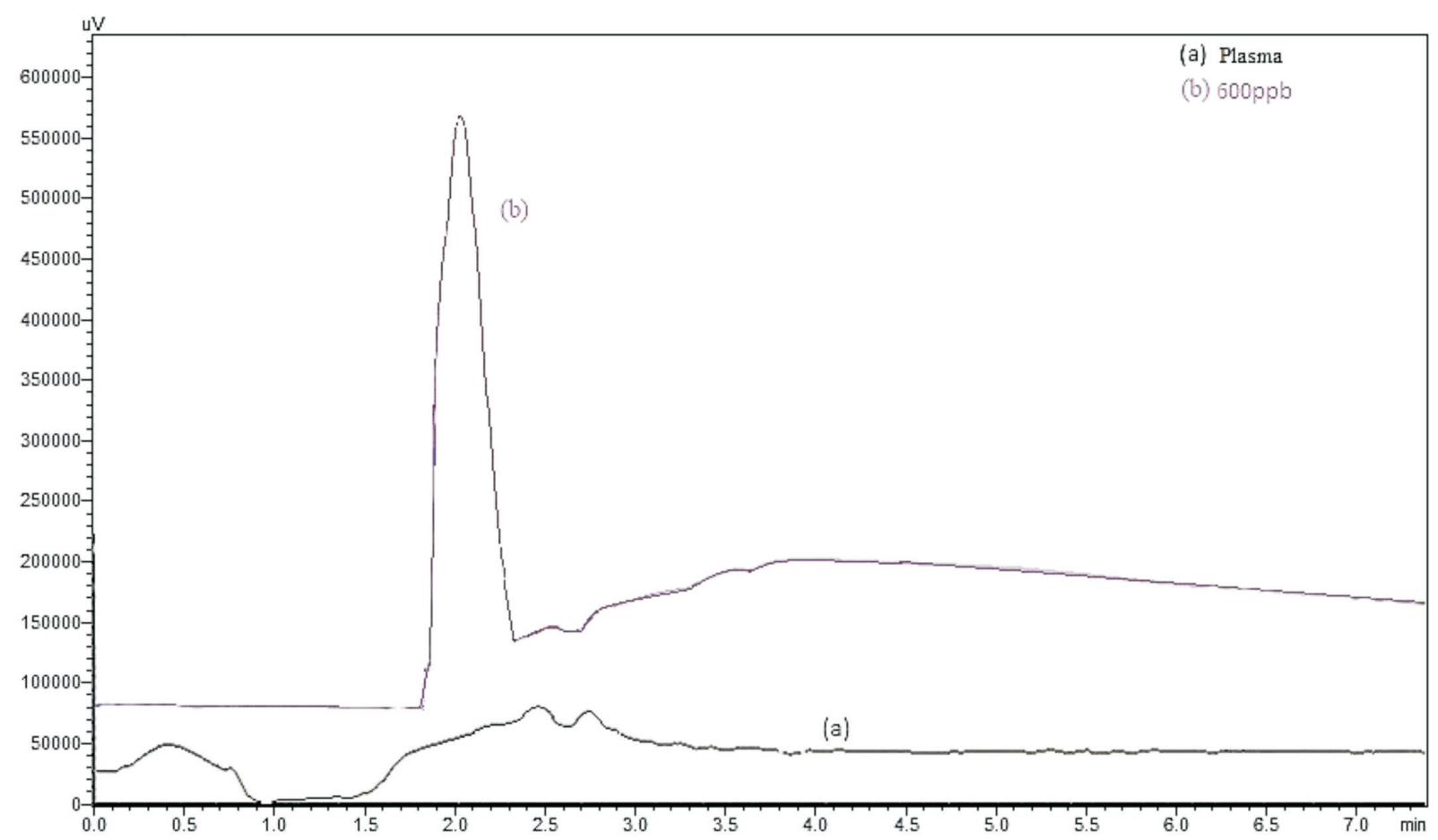

Figure 10 HPLC chromatograms, (a) before spiking with analyte in plasma and (b) $600 \mu \mathrm{g} \mathrm{L}^{-1}$ spiked of analyte in plasma after extraction via proposed method at optimum conditions.

frozen human plasma sample was obtained from the Iranian Blood Transfusion Organization (Tehran, Iran). It was thawed and allowed to reach room temperature and then used. In order to reduce the matrix effect, the plasma sample was diluted to $1: 10$, using deionized water. The relative recovery (RR) is obtained from the following equation:

$$
\mathrm{RR} \%=\mathrm{C}_{\text {found }}-\mathrm{C}_{\text {real }} / \mathrm{C}_{\text {added }} \times 100,
$$

where $C_{\text {found }}, \mathrm{C}_{\text {real }}$ and $\mathrm{C}_{\text {added }}$ are the concentrations of the analyte after the addition of a known amount of standard in a real sample, the concentration of the analyte in a real sample and the concentration of a known amount of standard, which was spiked to the real sample, respectively. The relative recoveries were between 88.3 and 95\% (Table 3) and show that matrix has negligible effect on the performance of the proposed method. The chromatograms of the plasma and urine samples before spiked (a) and after spiked (b) at $600 \mu \mathrm{g} \mathrm{L}^{-1}$ concentration levels are shown in Figs. 10 and 11, respectively.

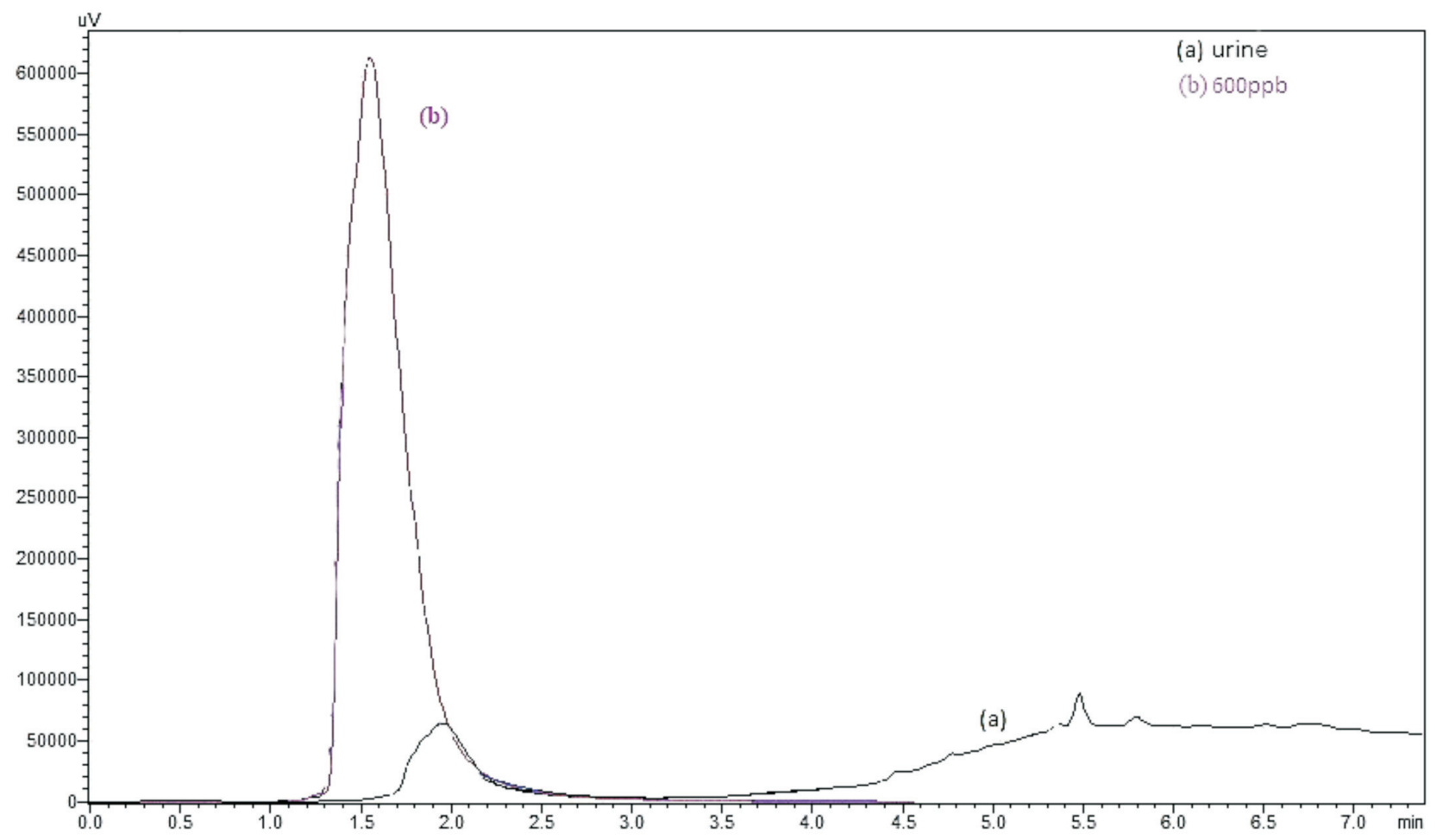

Figure 11 HPLC chromatograms, (a) before spiking with analyte in urine and (b) $600 \mu \mathrm{g} \mathrm{L}^{-1}$ spiked of analyte in urine after extraction via proposed method at optimum conditions. 


\section{Conclusion}

In this study, a novel molecular imprinted polymer has been prepared to extract and determine meropenem in human urine and plasma samples combining with HPLC. The MIP displayed large adsorption capacity, high selectivity and good stability for meropenem. Good precision, high quantities of recoveries, wide dynamic linear range, and a low limit of detection were achieved due to the powerful efficiency of the MIP-SPE method. The MIP-SPE procedure was applied for rapid and selective determination of meropenem from human urine and plasma samples followed by HPLC.

\section{Acknowledgement}

Financial support by Lahijan Branch, Islamic Azad University (Lahijan, Iran), during the period of this research is gratefully acknowledged.

\section{${ }^{s}$ ORCID iDs}

H.S. Amlashi:

A.P. Daryasari:

M. Soleimani:

orcid.org/0000-0001-9812-3997

orcid.org/0000-0003-4680-6969

orcid.org/0000-0003-2472-6415

\section{References}

1 J.R. Edwards, P.J. Turner, C. Wannop, E.S. Withnell, A.J. Grindey and K. Nairn, In vitro antibacterial activity of SM-7338, a carbapenem antibiotic with stability to dehydropeptidase I, Antimicrob. Agents Chemother., 1989, 33, 215-222.

2 L.R. Wiseman, A.J. Wagstaff, R.N. Brogden, H.M. Bryson, Meropenem. A review of its antibacterial activity, pharmacokinetic properties and clinical efficacy, Drugs, 1995, 50, 73-101.

3 C.M. Baldwin, K.A. Lyseng-Williamson and S.J. Keam, Meropenem: a review of its use in the treatment of serious bacterial infections, Drugs, 2008, 68, 803-838.

4 A. De Sarro, C. Imperatore, P. Mastroeni and G. De Sarro, Comparative convulsant potencies of two carbapenem derivatives in C57 and DBA/2 mice, J. Pharm. Pharmacol., 1995, 47(4), 292-296.

5 F. Scaglione, Can PK/PD be used in everyday clinical practice, Int. J. Antimicrob. Agents, 2002, 19, 349-353.

6 Y. Takeuchi, M. Sunagawa, Y. Isobe, Y. Hamazume and T. Noguchi, Stability of a $1 \beta$-methylcarbapenem antibiotic, meropenem (SM7338) in aqueous solution, Chem. Pharm. Bull., 1995, 43, 689-692.

7 M. Fukasawa, Y. Sumita, E.T. Harabe, T. Tanio, H. Nouda, T. Kohzuki, T. Okuda, H. Matsumura and M. Sunagawa, Stability of meropenem and effect of 1 beta-methyl substitution on its stability in the presence of renal dehydropeptidase I, Antimicrob. Agents Chemother., 1992, 36, 1577-1579.

8 C. Robatel, T. Buclin, P. Eckert, M.D. Schaller, J. Biollaz, and L.A. Decosterd, Determination of meropenem in plasma and filtratedialysate from patients under continuous veno-venous haemodiafiltration by SPE-LC, J. Pharm. Biomed. Anal., 2002, 29, 17-33.

9 J.G. Hardman, L.E. Limbird and A.G. Gilman (eds.), Goodman and Gilman's The Pharmacological Basis of Therapeutics, 10th edn., McGrawHill Medical Publishing Division, New York, 2001, 1214 pp.

10 R. Wise, M. Logan, M. Cooper, J.P. Ashby and J.M. Andrews, Meropenem pharmacokinetics and penetration into an inflammatory exudate, Antimicrob. Agents Chemother., 1990, 34, 1515-1517.

11 A. Leroy, J.P. Fillastre, F. Borsa-Lebas, I. Etienne and G. Humbert, Pharmacokinetics of meropenem (ICI 194,660) and its metabolite (ICI $213,689)$ in healthy subjects and in patients with renal impairment, Antimicrob. Agents Chemother., 1992, 36, 2794-2798.

12 H. Elkhaili, S. Niedergang, D. Pompei, L. Linger, D. Leveque and F. Jehl, High-performance liquid chromatographic assay for meropenem in serum, J. Chromatogr. B, 1996, 686, 19-26.
13 Y. Ozkan, I. Kucukguzel, S.A. Ozkan and H.Y. Aboul-Enein, A rapid, sensitive high performance liquid chromatographic method for the determination of meropenem in pharmaceutical dosage form, human serum and urine, Biomed. Chromatogr., 2001, 15, 263-266.

14 S. Bompadre, L. Ferrante, M. De Martinis and L. Leone, Determination of meropenem in serum by high-performance liquid chromatography with column switching, J. Chromatogr. A, 1998, 812, 249-253.

15 M. Ehrlich, F.D. Daschner and K. Kummerer, Rapid antibiotic drug monitoring: meropenem and ceftazidime determination in serum and bronchial secretions by high-performance liquid chromatography-integrated sample preparation, J. Chromatogr. B, 2001, 751, 357363.

16 J.E. Contejr, J.A. Golden, M.G. Kelley and E. Zurlinden, Intrapulmonary pharmacokinetics and pharmacodynamics of meropenem, Int. J. Antimicrob. Agents, 2005, 26, 449-456.

17 W.A. Krueger, J. Bulitta, M. Kinzig-Schippers, C. Landersdorfer, U. Holzgrabe, K.G. Naber, G.L. Drusano and F. Sorgel, Evaluation by Monte Carlo simulation of the pharmacokinetics of two doses of meropenem administered intermittently or as a continuous infusion in healthy volunteers, Antimicrob. Agents Chemother., 2005, 49, 1881-1889.

18 K. Ensing and T. De Boer, Tailor-made materials for tailor-made applications: application of molecular imprints in chemical analysis, Trends Anal. Chem., 1999, 18, 138-145.

19 C. Dauwe and B. Sellergren, Influence of template basicity and hydrophobicity on the molecular recognition properties of molecularly imprinted polymers, J. Chromatogr. A, 1996, 753, 191-200.

20 X. Jiang, C. Zhao, N. Jiang, H. Zhang and M. Liu, Selective solidphase extraction using molecular imprinted polymer for the analysis of diethylstilbestrol, Food Chem., 2008, 108, 1061-1067.

21 E. Caro, R.M. Marce, F. Borrull, P.A.G. Cormarck and D.C. Sherrington, Application of molecularly imprinted polymers to solid-phase extraction of compounds from environmental and biological samples, Trends Anal. Chem., 2006, 25, 143-154.

22 B.J. Brune, J.A. Koehler, P.J. Smith and G.F. Payne, Correlation between adsorption and small molecule hydrogen bonding, Langmuir., 1999, 15, 3987-3992.

23 M.M. Sanagi, S. Salleh, W.A.W. Ibrahim, A. Abu Naim, D. Hermawan, M. Miskam, I. Hussain and H.Y. Aboul-Enein, Molecularly imprinted polymer solid-phase extraction for the analysis of organophosphorus pesticides in fruit samples, J. Food Compos. Anal., 2013, 32, 155-161.

24 A. Ellwagner, C. Berggren, S. Bayoudh, C. Crecenzi, L. Karlsson, P.K. Owens, K. Ensing, P. Cormack, D. Sherrington and B. Sellergren, Evaluation of methods aimed at complete removal of template from molecularly imprinted polymers, Analyst, 2001, 126, 784-792.

25 C.Y. He, Y.Y. Long, J.L. Pan, K.A. Li and F. Liu, Application of molecularly imprinted polymers to solid-phase extraction of analytes from real samples, J. Biochem. Biophys. Methods., 2007, 70, 133-150.

26 B. Sellergren, Polymer and template-related factors influencing the efficiency in molecularly imprinted solid-phase extractions, Trends Anal. Chem., 1999, 18, 164-175.

27 Y.W. Chou, Y.H. Yang, J.H. Chen, C.C. Kuo and S.H. Chen, Quantification of meropenem in plasma and cerebrospinal fluid by micellar electrokinetic capillary chromatography and application in bacterial meningitis patients, J. Chromatogr. B, 2007, 856, 294-301.

28 R. Denooz and C. Charlier, Simultaneous determination of five $\beta$-lactam antibiotics (cefepim, ceftazidim, cefuroxim, meropenem and piperacillin) in human plasma by high-performance liquid chromatography with ultraviolet detection, J. Chromatogr. B, 2008, 864, 161-167.

29 A. Dupuis, P.H. Minet, W. Couet, P.H. Courtois and S. Bouquet, Rapid and sensitive determination of meropenem in rat plasma by high performance liquid chromatography, J. Liq. Chromatogr. Relat. Technol., 1998, 21, 2549-2560. 